without obtaining a first degree. Only $1 \cdot 4$ per cent of the last group had failed thcir final examinations; most withdrew from their courses because of academic failure $(9.5$ per cent of the potential output), illness $(0.5$ per cent), disciplinary reasons $(0 \cdot 1$ per cent) or other unspecified reasons.

The largest proportion of abandoned courses were in engineering and technology; only 68 per cent of students graduated in the normal period, and a little over 76 per cent had done so by the following year. The percentages for medicine and dentistry were similar $(69$ and 65 per cent respectively), but in this case 87 per cent had obtained their first degree at the end of a further year. In the biological and physical sciences 80 per cent of students graduated at the normal time, and 85 per cent by the following year. Arts and social sciences had the highest rate of success; more than 80 per cent of the potential graduated in 1966 and by the following year the proportion was about 90 per cent.

More science and technology students withdrew through academic failure (10 per cent and almost 19 per cent respectively) than did arts (4.8 per cent) or social science students $(5.4$ per cent). Withdrawal for academic reasons was always greatest in the first year of courses. Illness, which was also greatest in the first year, caused the greatest number of withdrawals in the arts and social sciences. On the whole more men than women left for academic reasons, and a larger proportion of women left for "other reasons".

These trends are in general agreement with the findings of previous surveys of the progress of students entering universities in 1952, 1955 and 1957 carried out by the UGC (University Development 1957-62). The largest proportion of students who abandoned their courses were then as now technologists and pure scientists. Although direct comparison between the two sets of findings is difficult, it seems that the reduction from 14.2 to 13.3 per cent in the total population of students who failed to complete their courses is due to a reduction in the number who failed their finals; there has been no significant change in the proportion leaving for academic or other reasons.

\section{Gas on Tap}

There are signs that the Gas Council is on the way to winning its prolonged battle with the companies which have found gas in the North Sea. For a long time the gap between the two sides seemed unbridgeable, but now that a compromise has been reached with two of the companies, it seems that the Gas Council has the better of it. The argument, of course, is over price, and began when the companies asked for 5 pence a therm for the gas and the council offered $1 \cdot 8$ pence. Last week the Arpet group, one of the groups which has found gas in the Hewett Field, settled for a price of $2 \cdot 87$ pence per therm, on almost exactly the same conditions as Phillips accepted six months ago. Arpet has had little choice, in fact, because both finds were in the same field, and although the Arpet negotiators originally expressed disgust at the terms accepted by Phillips, they had in the end to accopt the same terms themselves. The contract signed last week assumes a 60 per cent load factor, and when the annual contract quantity is exceeded, the extra gas will be sold for 2.025 pence a therm. Like the Phillips contract, the Arpet agreement lasts for 25 years.
The two agreements will provide the Gas Council with some 600 million cubic feet of gas a day, about half the present daily demand in Britain. Rather more than half of this will be supplied by Phillips, rather less than half by Arpet. There are also signs of progress in the negotiations over the other major gas field, on the Leman Bank. The Gas Council has now negotiated with the Shell-Esso Group a temporary agreement to cover the supply of test gas from the Leman Bank field to the terminal at Bacton (see map). The price agreed for the interim contract is the same as the Arpet price, 2.87 pence per therm, and although this does not officially create a precedent for the full contract, which is to be signed by October 1, it may be significant. It is now being generally assumed that the Shell-Esso contract will differ only in detail from those signed by Phillips and Arpet. There will be some differences, because the Leman Bank is larger and farther out, and the gas it contains is free from sulphur, unlike the gas from the Hewett Field.

The council will be cheerful to have these contracts under its belt, although it is important to stress that the Shell-Esso agreement is only an interim measure to enable the council to test its pipelines and engineering facilities before the gas comes on to full stream next winter. Despite a price which must be disappointing

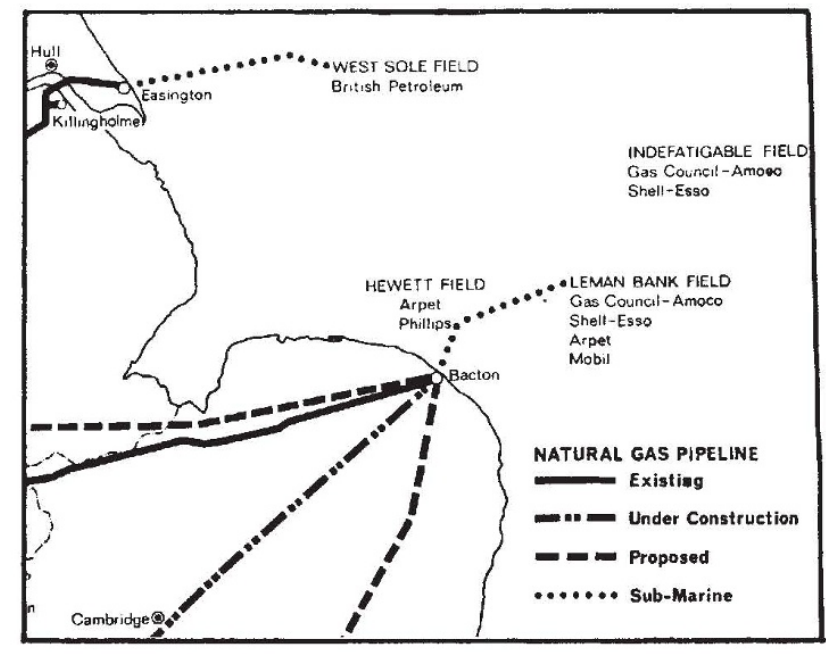

to the oil companies, there is no clear evidence that their enthusiasm for exploration in the North Sea is wilting. Meanwhile, the idea of setting up a National Hydrocarbons Corporation is again having an airing. This idea, originally put forward by a Labour Party group, would provide for a corporation with the power to search for oil and gas in the North Sea and act as a monopoly buyer for natural gas. If the corporation were set up, its crucial role would not arise until 197071, when the leases for some of the areas in the North Sea come up for renewal. This period will in any cace be interesting, because it will show whether the companies are still interested in prospecting, despite what they will undoubtedly regard as a low return.

\section{Creative Computers}

THere have been many science fiction stories since the beginning of the computer age nearly twenty years 
ago endowing computers with human, and even godlike, characteristics, but they have always lacked one essential ingredient-creativity, in other words, imagination, intuition and emotion. An exhibition opened this week at the Institute of Contemporary Arts in London that attempts to narrow this gap between the computer and the more humane arts. Jaisa Reichardt, who has worked since 1965 to organize and finance the exhibition, admits that it is not wholly successful in this attempt. "There are no heroic claims to be made," she says, "because computers have so far neither revolutionized music, nor art, nor poetry, in the same way that they revolutionized science." She stresses that the most important point of the exhibition is that "people who would have never put pencil to paper or brush to canvas have started to make images ... which approximate to what we call 'art' and put in public galleries".

It is just this point that many people will find disturbing as an extension of the already heated argument-when is an object considered "a work of art" ? Many of the pictures and graphics produced by computer programs do not raise this question either because they are simply two or three-dimensional projections of mathematical or physical phenomena, or because they are computerized transformations of a drawing or photograph, such as the picture of Marilyn Monroe (see illustration) that has been subjected to a

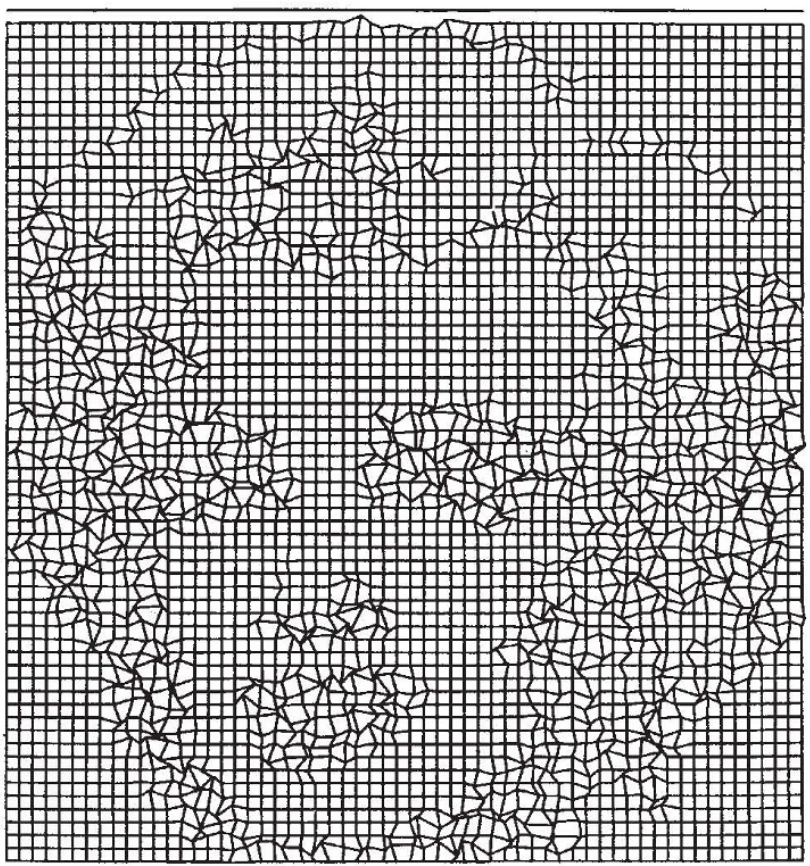

process of deforming. At the other extreme, the computer can be treated like any other medium, as a means of projecting an artist's concept. Several examples in the exhibition were produced by artists starting with an idea and then working out the program necessary to produce the desired effect. It is in the middle ground, where the program defines the basic set of parameters and leaves the various possibilities within them to chance, that the questions arise. A scientist at the Bell Telephone Laboratories, Michael Noll, produced a series of pictures based on an analysis of a black and white Piet Mondrian painting; when he showed both the original and one of the computer variations to a number of people, only 28 per cent correctly identified the Mondrian and 59 per cent preferred the computer picture. This does not mean to say that the computer could be considered more creative than Mondrian, but it does raise questions about aesthetics. Professor Dennis Gabor in an article in Encounter in 1960 said, "I sincerely hope that machines will never replace the creative artist, but in good conscience I cannot say that they never could".

In other creative fields, especially music and poetry, but also in sculpture and dance, the computer is being used extensively. Musicians especially are using it both to aid the composer in producing a score, which can then be played by the usual musical instruments, or to produce actual sounds in place of any other instruments and to any degree of complexity desired. The composing program allows the computer to make some of the choices-such as pitch, number of notes, intervals, duration-that the composer would normally make. In this way computer music is merely an extension of experimental works in the areas of electronic music and chance already being composed by such musicians as Karlheinz Stockhausen, John Cage and Cornelius Cardew.

Computers may not be creative in their own right, but this exhibition certainly shows that they can be used with artistic imagination, as this poem from the Manchester University Computer persuasively shows:

Darling sweetheart,/ You are my avid fellow feeling My affection curiously clings to your passionate wish My liking yearns for your heart

You are my wistful sympathy; my tender liking Yours beautifully, M.U.C.

\section{Costly Airbus}

THE three aviation ministers who met last week in Paris to discuss the future of the European airbus project seem to have taken a firm line. The project has been plunged into gloom by the recent announcement that the cost estimates were far wide of the mark. Instead of the total bill being something like $£ 190$ million, it has now increased to $£ 285$ million. The three governments have therefore agreed to postpone a decision on the airbus while further calculations are made. Over the next two months or so, the manufacturers will re-examine the costs of the project, in the hope either of reducing them to more manageable proportions, or of trying to produce a better aeroplane for the same cost. The ministers, from France, West Germany and Britain, asked the companies to produce the revised specifications by November. At the same time, the ministers produced a joint communiqué which urged the companies to produce an aircraft "even better adapted to the recent evolution of the market and to international competition".

Tt now seems very unlikely that the costs can be actually reduced, so the best hope is that a better acroplane can be put together for the same money. Most of the increase in cost has occurred on the airframe, which is principally the responsibility of Sud Aviation. It now seems that the design of the aircraft is more or less settled, and the companies involved 